\title{
Analysis and Adoption of Coffee Technologies in Major Coffee Growing Areas: The Case of Wombera District, Metekel Zone North Western Ethiopia
}

\author{
Desalegn Teshale Woldie \\ Ethiopian Institute of Agricultural Research, EIAR \\ Pawe Research Centre, P.o.Box 25, Pawe Ethiopia
}

\begin{abstract}
The main objective of this study was identifying factors which affect the adoption of coffee technologies in Wombera district of Metekel zone, Benishangul Gumuz national regional state, Ethiopia. The study used crosssectional farm household level data collected from 111 randomly selected sample households in 2018. Both descriptive and econometric methods have been used to analyze the data. The descriptive statistics were utilized to compare adopters and non-adopters. The logit model was employed to assess the adoption determinants of coffee. Accordingly, the descriptive result showed that significant mean difference was observed between adopters and non-adopter in terms of number of oxen ownership, owning spade/shovel and being a model farmer. The result of logit model indicted that number of oxen ownership, being a model farmer, adult literacy and owning pruning shear were found to positively influenced the adoption of coffee technology. Whereas household marital status and owning radio influenced adoption of coffee technology negatively. The finding of this study revealed that educating farmers through formal or informal programs, strengthening and increasing the number of model farmers by increasing their production skill, provision of pruning scissor and improving the livestock sector mainly oxen shall be good policy recommendations.
\end{abstract}

Keywords: Wombera, Adoption, coffee, Logit model

DOI: $10.7176 / \mathrm{JESD} / 10-19-08$

Publication date:October $31^{\text {st }} 2019$

\section{INTRODUCTION}

Coffee is one of the most important agricultural crop that greatly contributes for the performance of the Ethiopian economy. It is an important export commodity, contributing $41 \%$ of the country's total foreign exchange earnings and about $10 \%$ of the gross domestic product (Amamo, 2014). Over 25\% of the population of Ethiopia, representing 20 million people, are dependent on coffee for their livelihoods (FAO, 2000). In otherward, majority of the small holders' livelihood is dependent on coffee cultivation and hence coffee has a paramount contribution in the overall economy of the country.

Ethiopia is the world's fifth largest coffee producer next to Brazil, Vietnam, Colombia, and Indonesia, contributing about 4.2 percent of total world coffee production and Africa's top producer, with an estimated 500,000 metric tons in 2012/2013 (Tefera and Tefera, 2012).

Coffee is one of the most important globally traded agricultural commodities, with consumption occurring mostly in developed countries and production in developing countries. Ethiopia is the biggest exporter of coffee in Africa, it accounts for $22 \%$ of the country's commodity exports. Ethiopia's coffee Arabica is valued for its unique taste Nearly $95 \%$ of the country's coffee is cultivated by an estimated 4 million primarily smallholder, often poor farming households.

Despite its importance, coffee production system is largely characterized by traditional methods of production and low level of improved technology availability and uptake. Different empirical evidence indicated that farmers' decision on adoption of agricultural innovation can be influenced by different factors associated with socioeconomic, institutional, demographic and physical characteristics. Accordingly, identifying the bottlenecks in coffee adoption system requires due emphasis. Therefore, assessing the adoption system, availability and access of improved coffee varieties and associated technologies.

Coffee production is almost exclusively concentrated in the two regions of Ethiopia, Oromia and the Southern Nations, Nationalities, and People Regions (SNNPR). Research centers, notably Jimma research center in collaboration with other centers like Pawe, Wondogenet and others have generated and released a lot of improved coffee varieties and agronomic practices. Besides, research centers have been involved in technology promotion, dissemination and popularizing in coffee growing areas across the country.

This research was conducted in Wombera District of Metekel zone. It aims to identify the opportunities and challenges, marketing and adoption of coffee sub sector. The study area is one of the best quality coffee producing area. But smallholder farmers are not yet benefited from their production. Hence, studying adoption of coffee technology and suggest possible policy options to enhance the production and productivity of coffee in the district that in turn support the livelihood of coffee farm households. 


\subsection{Research Questions}

This research was supposed to answer the following key questions.

1. What are the major opportunities and challenges of coffee production in Wombera district?

2. What are the available coffee technologies, and how do get it?

3. What are the major factors to adopt coffee technology?

\subsection{Objective of the Study}

The general objective of the study was to assess and document the coffee production and adoption status of available technologies in Wombera district.

\section{Specific objectives;}

1. To assess the coffee technology adoption decision behavior

2. To identify the determinant factors of coffee technology adoption.

\subsection{Significance, Scope and Limitation of the Study}

The results of this study will significantly contribute for policy brief in Wombera district in particular and other coffee growing areas. The scope of the study focuses only on adoption and status of coffee. Since coffee adoption $\&$ impact study implemented as a project, aggregate project level report will be released. But this research confined to Womebra district.

\section{RESEARCH METHODOLOGY}

In this section description of research area, sampling methodologies, data collection, and method of data analysis were presented.

\subsection{Description of the study area}

Wombera district was one of the seven districts in Metekel Zone Benshangul Gumuz Region. The district is bordered with Guba and Dangur in the west, Kamesh in the East, Bullen in the north and Assosa \& Kemash in the south directions. Its total land area coverage is 736,425 ha with total population of $97,152(48,479$ males and 48673 female) (WDAO, 2018). The altitude ranges from 600 to 2731 masl. The district has composed of twenty rural kebles or administrative peasant associations. Debrezet is the capital of the district located in the high land area of the district and $654 \mathrm{~km}$ far from Addis Ababa.

Crop production and livestock rearing were the major livelihood strategies of the district. Besides, they practice coffee based agro-forestry practices. From the total twenty kebeles ten of them are coffee producers. Maize, wheat, sorghum, teff, coffee was some of the important crops. Cattle, sheep, goat, donkey, mule and chicken were an important livestock species reread by farmers. Fruit trees like mango is also produced in the lowland part of the district.

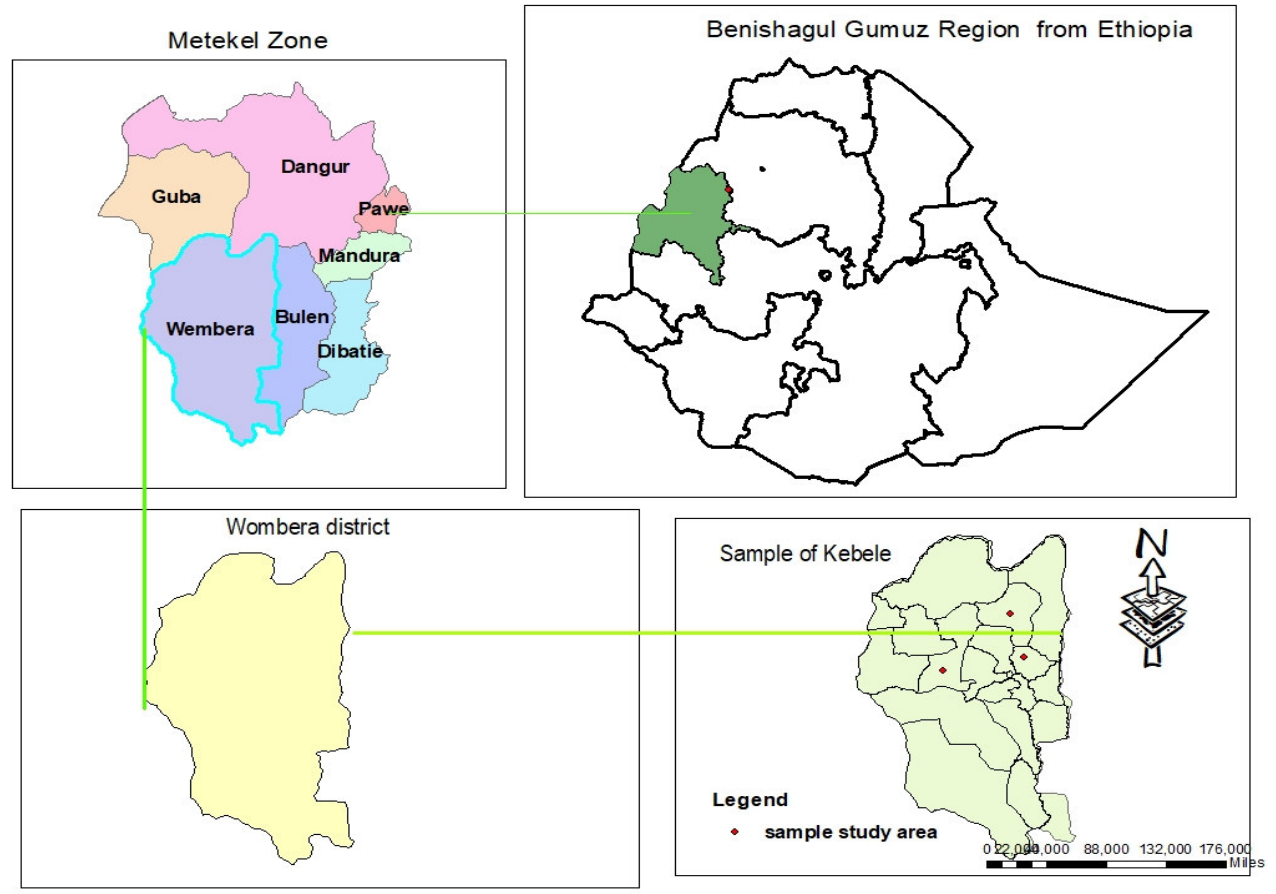

Figure 1. Study map 


\subsection{Data type, Source and Method of Analysis}

Both primary and secondary data sources were used to collect quantitative and qualitative data. Primary data on demographic characteristics, socioeconomic and institutional factors and other relevant data assumed to meet the objective of the study were collected from randomly selected farm households in the study district. Primary data was collected using structured questioner which was administered by trained enumerators with the supervision of the researcher. The questioner was designed and pre-tested in the field for its validity and content, and to make the overall improvement of the study and in line with the objectives of the study. While secondary data were collected from different published and unpublished sources, such as regional office of agriculture, district agricultural offices and kebele development agents were consulted to generate relevant data for the study.

\subsection{Sampling methodology, size and data collection}

In order to meet the objective of any study determining the appropriate sample size and method of size determination is crucial. Accordingly, three stage random sampling were employed to select respondent households. Wombera district were purposively selected in its high potential of coffee production and the intention of the project objective. In the first stage ten coffee producing kebeles were stratified in to high, medium and low coffee growers based on its production potential, and area coverage. In the second stage, one kebele from each stratum were selected randomly. In the third stage, given fresh list of households in the respective kebeles, using systematic random sampling technique with probability proportion to sample size total of 111 coffee producer farmers were subjected to survey interview.

\section{Method of Data Analysis techniques}

The collected data were analyzed using descriptive and econometrics statistics. Descriptive statistics such as mean, standard deviation, frequency, percentage, graph were used to describe the different categories of sample units with respect to different socioeconomic characteristics. Besides, inferential statistics such as chi-square test (for dummy variables) and t-test (for continuous variables) were used to compare and contrast different categories of sample units with respect to the coffee technology users and non-users.

The econometric model applied for this study to estimate the probability that a given household will adopt coffee technology was Binary logit regression model. It is appropriate model where the dependent variable takes binary response in this case adopters and non-adopters. Logit regression is a linear probability model for binary response where the response probability is evaluated as a linear function of the explanatory variables (Maddala, 1986; Wooldridge, 2010).

Therefore, the dependent variable which was used with logit model is coffee technology adoption, taking the values 1 or 0 . The value 1 indicates a farmer who adopted coffee technology, 0 otherwise. In this study, adopters were defined as farmers who planted at least one of the improved coffee varieties or at least practicing improved coffee management techniques and practices, and non-adopters were defined as farmers who did not plant the improved varieties and/or improved agronomic practices.

The simple linear regression model;

$Y_{i}=\beta_{O}+\beta_{i} X_{i}+u_{i}$

Where: $Y_{i}$ stands for adoption of coffee technologies with a value of 1 for adopters and 0 for non-adopters.

$X_{i}$ refers to a farmer's characteristics or explanatory variables for the $i^{\text {th }}$ farmer.

$u_{i}$ refers to the error term which is independently distributed random variable with a mean of zero.

$\beta$ 's coefficients of explanatory variables.

Even though equation (1) looks like a typical linear regression model, the dependent variable is a binary response. Hence, it is called a linear probability model (LPM). In the regression model, however, because the dependent variable is adoption taking the value 1 or 0 , the use of linear probability models (LPM) is a major problem. The predicted value can fall outside the relevant range of 0 to 1 probability value. Therefore, to overcome the problem associated with the linear probability model, the logit model was used as it has been recommended by (Gujarati, 2009). The model was, therefore, estimated by using Maximum Likelihood Estimation (MLE) procedures. Therefore, the logistic cumulative probability function for adopters is represented by:

$P_{i}=\frac{1}{1+e^{-z}}=\frac{e^{z}}{1+e^{z}}$

Where $P_{i}$ is the probability that the $i^{\text {th }}$ farmer adopted the coffee technology and that $P_{i}$ is nonlinearly related to $Z\left(X_{i} \beta_{s}\right)$.

$Z_{i}=\beta_{O}+\beta_{i} X_{i}+\ldots \ldots \beta_{n} X_{n}$ represents the base of natural logarithms.

The probability of non-adopters is then , $1-P_{i}$.

$1-P_{i}=\frac{1}{1+e^{z}}$

Therefore, the odds ratio in favor of adoption of coffee technology is

$\frac{P_{i}}{1-P_{i}}=\frac{e^{z} /\left(1+e^{z}\right)}{1 /\left(1+e^{z}\right)}=e^{z}$ 
Again in order to estimate the logit model, the dependent variable was transformed by taking the natural log of Equation 4 as follows;

$L_{i}=\left(\ln \frac{P_{i}}{1-P_{i}}\right)=Z_{i}=\beta_{O}+\beta_{i} X_{i}+\ldots \ldots \beta_{n} X_{n}$

Where: $L_{i}$ is the log of the odds ratio, linear not only in the explanatory variables but also in the parameters. $L$ is the logit, and hence it is the logit probability model. It is, thus, $P_{i}$ ranges between 0 and 1 .

Hence, the Logistic model for the logs of odds of improved coffee technology adoption was specified as follows: $Y_{i}=\beta_{O}+\beta_{i} X_{i 1}+\beta_{2} X_{i 2} \ldots \ldots \ldots \beta_{k} X_{i k}+u_{i}$

Where, $Y_{i}$ is the $\log$ odds of adoption for the $i^{\text {th }}$ farmer; $X_{i}$ the explanatory variables and $u_{i}$ is the error term.

\section{RESULT AND DISCUSSION}

This chapter presents the major findings of the adoption of coffee technology packages. The status of adoption and use of coffee production package, current practices of coffee technology package were discussed. Besides, the different socioeconomic, demographic and institutional factors that influenced the adoption of coffee technology adoption were discussed. Moreover

\subsection{Descriptive Results}

Continuous Variables: Table 1 below presents the t-test comparison of means of the continuous variables by adoption status of coffee technology grower farmers. The average age of sampled households in the study area was 42.61 years with minimum and maximum ag of 26 and 70 years respectively. Age was one of the demographic characteristics assumed to influence the decision to adopt new technologies, but this study found no significant difference in terms of age between farmers who had adopted improved coffee technologies and those who had not. Education is one of the important human capital that assumed to influence the adoption decision, since literate farmers would have a greater ability to obtain, process, and use information about improved technologies than lower grades or illiterate farmers. The educational attainment of the household head in the study area was 0.31 years with standard deviation of 3.18. However, no significant difference was observed in the level of education between adopters and non-adopters of improved coffee technology. The average family size was 6.1 with standard deviation of 1.7. Regarding to adoption status, family size does not show significant mean difference between adopters and non-adopters. The average number of oxen ownership in the study area was 1.7 with minimum and maximum of 0 and 6, respectively. Moreover, the results show that there is a significant mean difference was observed between coffee adopters and non-adopters in terms of oxen ownership. It showed that relatively higher number of oxen were exist in adopters than non-adopters.

The average landholding in the study area was 1.7 ha with standard deviation of 1.46. The land holding (own) included were cultivated land, grazing land, bush land or uncultivated land, and land covered by perennial tree crops. Besides, from the total sample population 11.7\%( 13) households did not have their own land. Moreover, the average land holding for adopters were 2.98 ha with standard deviation of 2.21 whereas for non-adopters the average land holding was 2.78 ha with standard deviation of 1.96 . Besides the share of coffee land from the total land was $14 \%$ and $16 \%$ for adopters and non-adopters, respectively with no significant mean difference.

Table 2: Descriptive summary of continues

\begin{tabular}{|c|c|c|c|c|c|c|c|c|}
\hline \multirow[t]{2}{*}{ Variable } & \multirow[t]{2}{*}{ Unit } & \multicolumn{2}{|l|}{ Full } & \multicolumn{2}{|c|}{ Adopters } & \multicolumn{2}{|c|}{ Non-Adopters } & \multirow[t]{2}{*}{ t-value } \\
\hline & & Mean & St. Dev. & Mean & St. Dev & Mean & St. Dev & \\
\hline HH-age & Years & 42.61 & 9.18 & 42.43 & 9.05 & 42.69 & 9.3 & 0.14 \\
\hline HH-Education & Grade & 0.31 & 3.18 & 3.08 & 3.19 & 3.39 & 3.19 & 0.47 \\
\hline Family size & Head & 6.8 & 1.7 & & & & & \\
\hline Livestock & TLU & 7.63 & 6.32 & 10.03 & 6.52 & 6.52 & 6.06 & -2.52 \\
\hline Own Land holding & hectare & 2.8 & 2.03 & 2.98 & 2.21 & 2.78 & 1.96 & -0.49 \\
\hline Oxen & Number & 1.7 & 1.46 & 2.11 & 1.58 & 1.54 & 1.37 & $-0.95 *$ \\
\hline Extension Contact & days & 4.5 & 9.7 & 4.7 & 6.59 & 4.38 & 11.02 & -0.18 \\
\hline
\end{tabular}

$* *$ and $*$, denotes significance level at $5 \%$ and $10 \%$, respectively

Source: Survey result (2017)

Dummy Variables: Table 2 below presents the major findings for dummy variables respective to coffee adoption status. From the total sample population, $91 \%$ of the respondent were male headed whereas the remaining $(8 \%)$ female headed. Regarding to adoption status, $88.5 \%$ of male headed households were adopters and only $11.4 \%$ were female headed households, whereas in the non-adopters group $93.4 \%$ of male headed and $6 . \%$. The chi 2 value showed there is no significant mean difference. From the total sample $90.9 \%$ of the respondents were married and living with their spouses. But, there was no observable difference among adopters and non-adopter's household heads in terms of their marital status.

The study result suggests that, the literacy rate in the study area was $76.57 \%$. The figure is very relative to the regional (Benishangul Gumuz) and the country level. The possible explanation might be, the district is located 
far away from the regional government which leads poor infrastructural development (road, school, telecom, health facilities, veterinary services, etc.).

The majority of the sample household heads (76.5\%) were literate. At the same time the majority of adopters and non-adopters literacy rate was $83 \%$ and $74 \%$ respectively. The chi-square value showed no systematic association between the level of education and the adoption of coffee technologies. Being a model farmer would have in a better opportunity to access the technologies, information and other important farming operations. Accordingly, the number of model farmers in the study district was $45.94 \%$. Regarding to the adoption status, $51.4 \%$ adopters and $30.3 \%$ of non-adopter's farmers were counted as model farmers. The chi2 value showed there is significant mean difference were observed between adopters and non-adopters in terms of model farmer at $10 \%$ significant level.

Table 3: Descriptive summery of Dummy Variables

\begin{tabular}{|c|c|c|c|c|c|c|c|c|}
\hline \multirow[t]{2}{*}{ Variable } & \multicolumn{3}{|c|}{ Total } & \multicolumn{2}{|c|}{ Adopters } & \multicolumn{2}{|c|}{ Non-Adopters } & \multirow[t]{2}{*}{ Chi2 } \\
\hline & Category & No & $\%$ & no & $\%$ & $\mathrm{~N}$ & $\%$ & \\
\hline \multirow[t]{2}{*}{ HH-Sex } & Male & 102 & 91.89 & 31 & 88.57 & 71 & 93.42 & \multirow[t]{2}{*}{0.75} \\
\hline & Female & 9 & 8.1 & 4 & 11.43 & 5 & 6.5 & \\
\hline \multirow[t]{2}{*}{ Marital Status } & Married & 101 & 90.9 & 30 & 85.7 & 71 & 93.4 & \multirow[t]{2}{*}{1.74} \\
\hline & Unmarried & 10 & 9.1 & 5 & 14.3 & 5 & 6.6 & \\
\hline \multirow[t]{2}{*}{ Adult Literacy } & Literate & 85 & 76.57 & 29 & 82.85 & 56 & 73.68 & \multirow[t]{2}{*}{1.12} \\
\hline & illiterate & 26 & 23.42 & 6 & 17.14 & 20 & 26.31 & \\
\hline \multirow[t]{2}{*}{ Access to credit } & Yes & 51 & 45.94 & 14 & 40 & 37 & 48.7 & \multirow[t]{2}{*}{0.73} \\
\hline & No & 60 & 54.05 & 21 & 60 & 39 & 51.3 & \\
\hline \multirow[t]{2}{*}{ Model Farmer } & Yes & 41 & 36.93 & 18 & 51.4 & 23 & 30.3 & \multirow[t]{2}{*}{$4.61 *$} \\
\hline & No & 70 & 63.06 & 17 & 48.57 & 53 & 69.7 & \\
\hline \multirow[t]{2}{*}{ Membership of any organization } & Yes & 56 & 50.4 & 20 & 57.1 & 36 & 47.37 & \multirow[t]{2}{*}{0.92} \\
\hline & No & 55 & 49.6 & 15 & 42.85 & 40 & 52.6 & \\
\hline
\end{tabular}

$* *$ and $*$, Denotes significance level at $5 \%$ and $10 \%$, respectively Source: Survey result (2017) Asset ownership of the respondents:

Asset included in this study was those that were assumed to produce for coffee production or for any agricultural operation. It included pruning scissors, motor pump, saw, spade, shovel, solar, and other equipment fond at household level. As shown in table 4 below, 94\% (105) did not have any type of pruning scissors until in the survey year (2017). Moreover, the survey result revealed that $51 \%$ of the respondents were access to credit that help them to purchase fertilizer, herbicide, pesticide and other inputs required for agricultural production. However, there is no significant mean difference between adopters and non-adopters in terms of credit access. At the same time $51.5 \%$ of the respondents were unable to obtain credit to buy improved coffee seed/seedling in the last ten years. From the total sample population, $83 \%$ of the respondents possess their own spade and or shovel. It is an important asset for coffee production. Besides, there was a significant mean difference was observed between adopters and nonadopters in terms of ownership of spade/shovel.

Table 4: Characteristics of Asset ownership and adoption status.

\begin{tabular}{lllllllll}
\hline \multirow{2}{*}{ Asset Types } & \multicolumn{3}{c}{ Total } & \multicolumn{3}{c}{ Adopters } & \multicolumn{3}{c}{ Non-adopters } & chi2 \\
& Category & No & \% & No & \% & No & \% & \\
\hline Owning Pruning scissors & Yes & 6 & 5.71 & 3 & 8.57 & 3 & 4.12 & 1.00 \\
& No & 105 & 94.29 & 32 & 91.43 & 73 & 65.76 & \\
Owning radio & Yes & 89 & 80.18 & 29 & 82.85 & 60 & 78.94 & 0.13 \\
& No & 22 & 19.81 & 6 & 17.14 & 16 & 21.05 & \\
Owning motor pump & Yes & 3 & 2.7 & 2 & 5.71 & 1 & 1.31 & 1.76 \\
& No & 108 & 97.3 & 35 & 94.29 & 75 & 98.68 & \\
Owning saw & Yes & 45 & 40.54 & 15 & 42.85 & 30 & 39.47 & 0.11 \\
Owning spade/shovel & No & 66 & 59.46 & 20 & 57.14 & 46 & 60.53 & \\
& Yes & 93 & 83.78 & 25 & 71.43 & 68 & 89.47 & $5.74 * *$ \\
Owning solar & No & 18 & 16.21 & 10 & 28.57 & 8 & 10.52 & \\
Owning mobile phone & Yes & 65 & 58.55 & 24 & 68.57 & 41 & 53.95 & 2.11 \\
& No & 46 & 41.44 & 11 & 31.43 & 35 & 46.05 & \\
Owning TV & Yes & 83 & 74.78 & 29 & 82.86 & 55 & 72.34 & 1.26 \\
& No & 27 & 24.32 & 6 & 17.14 & 21 & 27.63 & \multirow{2}{*}{1.66} \\
\hline
\end{tabular}

**, Denotes significance level at 5\%, Source: Survey result (2017) 


\section{Coffee Charachetrstics:}

From the total sample population, nearly all $(96 \%)$ households have been producing old coffee variety in the last ten years. However, their perception about origin and purity across coffee growing farmers varies. Accordingly, only $9 \%$ of the respondents were certain about they were producing local variety in the last ten years, while $56 \%$ of the respondents were considered it as local, but $35 \%$ were not sure of whether it is local or improved variety.

Table 5: Coffee type grown in the last ten years

\begin{tabular}{lcccc}
\hline Perception & \multicolumn{3}{c}{ Local variety $(\mathbf{N}=\mathbf{1 0 7})$} & Improved Variety(N=35) \\
\cline { 2 - 5 } & $\mathbf{N o}$ & $\mathbf{\%}$ & $\mathbf{N o}$ & $\mathbf{\%}$ \\
\cline { 2 - 5 } Certain & 10 & 9 & 11 & 32 \\
Modest & 62 & 58 & 15 & 43 \\
Not sure & 34 & 32 & & 14 \\
\hline
\end{tabular}

Source: survey result (2017)

\subsection{Econometric results of the Logit estimation}

The binary logistic regression (BLR) model was employed to examine the factors affecting the adoption of coffee technologies using maximum likelihood estimation. Since coefficients of logit model does not make sound interpretation, analyzing the marginal effects, which was calculated as the partial derivatives of the non-linear probability function, evaluated at each variable sample mean. Hence, the coefficients of the marginal effects after the logit model estimation were reported as shown in the table 5 below. Accordingly, 16 explanatory variables were employed in the logit model. From table five below only four variables were found to influence coffee adoption in the study area. These are marital status, livestock ownership, model farmer and owning motor pump.

Household marital status: Contrary to prior expectations, marital status of the household head and adoption of coffee technology was found to negatively statistically significant at less than $10 \%$ significance level. Keeping other variables constant, the probability of a household to adopt coffee technology will decrease by $48.1 \%$ if a household is married. The likely explanation is even though married households had access to information sharing with its spouse, the information shared might not be related to coffee production.

Number of oxen ownership: It is one of the important natural asset for the rural farming households. The logit result found that number of oxen ownership significantly and positively influenced adoption of coffee technology at less than 1\% significance level. Farmers who have larger number of are more likely to adopt coffee technology than those who have lower or do not have any oxen. Holding other variables constant, for each additional unit of oxen, the probability of a household to adopt coffee technology would increase by $23.8 \%$. The possible suggestion may be farmers use oxen for plowing purpose, and whenever needed they can sell oxen to buy improved seedling, fertilizer or any pesticide required for coffee production. Besides, farmers use manure and cow dung for their crops and vegetable gardens that increase the productivity of crops. The result is consistent with the findings of (Kapanda et al., 2005).

Model farmer: The study result suggests that being a model farmer the probability of a household to adopt coffee technology was found to significant and positive at 5\% probability level. The positive sign indicates that those household who are considered as a model farmer would likely to adopt coffee technology than who are not counted as model farmer. The marginal effects showed, keeping other variables constant, being a model farmer the probability of a household to adopt coffee technology will increase by $25.1 \%$.

Owning motor pump: The result suggests that ownership of motor pump was found to significantly and positively influenced the adoption of coffee technology at 5\% significance level. The positive relationship indicates, those households who own motor pump were more likely to adopt coffee technology than those who have no motor pump. The marginal effect showed the probability of households to adopt coffee technology will increase by $54.3 \%$ if households are owning motor pump.

Owning pruning scissor: Owning pruning scissor is crucial for coffee farming activity. Those farmers who have pruning scissor had higher probability to prune the coffee cultivation which increases the vegetation of the crop. Owning pruning scissor significantly and positively influenced the probability of adoption of the coffee technology package at less than 5\% significance level. The marginal effect indicates the probability of a household to adopt coffee technology will likely to increase by $66.7 \%$ if a farmer had pruning scissors. The result is consistent with the findings of (Musba, 2018).

Adult-literacy: As expected, it has a positive and significant relationship with the adoption of the coffee technology. Educated or literate respondents were $29.6 \%$ more likely to adopt than uneducated or illiterate at $10 \%$ significance level, holding other variables constant. This suggests that being literate would improve access to information, capability to interpret the information, understanding and analyzing the situation easily than illiterate farmers. Moreover, education enhances the capacity of individuals to obtain, process, and utilize information disseminated by different sources. On the other hand, educated farmers will find it easy to manage production and marketing activities which need certain skill of management. The finding is consistent with the findings of (Teferi et al., 2015) who found that education has a positive relationship with the adoption of improved maize varieties. 
Table 6: Estimation results of binary logit model

\begin{tabular}{lllcc}
\hline Variable & Coefficient & Robust St.Err & $\mathbf{P}>|\mathbf{Z}|$ & Marginal effect (dy/dx) \\
\hline HH heads sex & -0.072 & 1.24 & -0.954 & -0.013 \\
HH age & -0.035 & 0.03 & 0.270 & -0.006 \\
HH Martial & -2.137 & 1.09 & 0.052 & $-0.481^{*}$ \\
Literacy & 1.402 & 0.79 & 0.076 & $0.296^{*}$ \\
Oxen & 1.320 & 0.38 & 0.001 & $0.238^{* * *}$ \\
Livestock & 0.011 & 0.06 & 0.848 & 0.002 \\
Extension contact & 0.029 & 0.02 & 0.245 & 0.005 \\
Own land & -0.077 & 0.17 & 0.665 & -0.014 \\
Credit use & 0.461 & 0.72 & 0.525 & 0.084 \\
Model farmer & 1.294 & 0.57 & 0.028 & $0.251^{* *}$ \\
Membership of any organization & -0.611 & 0.69 & 0.377 & -0.116 \\
Owning Scissors & 3.348 & 1.58 & 0.034 & $0.667^{* *}$ \\
Owning motor-pump & 2.434 & 1.031 & 0.018 & $0.543^{* *}$ \\
Owning radio & -1.714 & 0.84 & 0.075 & -0.324 \\
Owning solar & 0.174 & 0.86 & 0.840 & 0.031 \\
Asset & 0.034 & 0.2 & 0.864 & 0.033 \\
\hline
\end{tabular}

No of Observations $=111$

Log pseudo Likelihood $=-37.6809$

Prob $>$ chi $2=0.0038$

Pseudo R2 $=0.3749$

Wald chi $(16)=3517$

$* * *, * *$ and $*$, denotes significant at $1 \%, 5 \%$ and $10 \%$ levels of significance respectively

\section{Conclusion and Recommendation}

This study was aimed to assess the coffee technology adoption in Wombera district of Metekel Zone. In the district coffee is an economically important cash crop, which serves as a major means of income for the livelihood of coffee producing families. According to the findings of this study, adoption of coffee technology was found to influenced positively by adult-literacy, marital status, oxen ownership, owning pruning scissors, owning motor pump and being model farmer. Whereas marital status and owning radio influenced adoption of coffee negatively. The government should improve adult education programs in the nearby rural villages which can play an important role in the process of adoption decision. The government should also provide and access the household assets which deemed necessary for coffee production like pruning scissors and motor pump.

\section{ACKNOLDGMENT}

I would like to thank Pawe Agricultural research for financial and logistics support to conduct this research. Besides, I would like to thank Wombera Distrct agricultural office staff who helped through facilitation during data collection.

\section{REFERENCES}

Amamo A.A (2014). Coffee production and marketing in Ethiopia. Eur J Bus Manag 6, 109-122.

FAO (Food and Agriculture Organization), 2000. Enhancement of Coffee Quality Socioeconomic study. Rome Italy.

Gujarati D.N (2009). Basic econometrics. Tata McGraw-Hill Education.

Kapanda K, Matiya G, N'Gong'Ola D.H, Jamu D, Kaunda E.K (2005). A logit analysis of factors affecting adoption of fish farming in Malawi: A case study of Mchinji Rural Development Program. Journal of Applied Sciences 5, 1514-1517.

Maddala G.S (1986). Limited-dependent and qualitative variables in econometrics. Cambridge university press.

Musba K (2018). Analysis of Adoption of Improved Coffee Technologies in Major Coffee Growing Areas of Southern Ethiopia. Journal of Innovative Systems Design and Engineering, 9(5): 9 - 17. .

Tefera A, Tefera T (2012). Coffee Annual Report. Journal of Global Agricultural Information Network.

Teferi A, Philip D, Jaleta M (2015). Factors that affect the adoption of improved maize varieties by smallholder farmers in Central Oromia, Ethiopia. Developing Country Studies 5, 15.

WDAO (Wombera District Agriculture Office) 2018. Annual Agricultural Activities Progress Report.

Wooldridge J.M (2010). Econometric Analysis of Cross section and Panel data. MIT press. 